\title{
Ролята на атопията към фунги в патогенезата на хроничния риносинуит
}

\author{
А. Куцаров¹, В. Цветкова² И., Стоянов \\ ${ }^{1}$ Клиника УНГ-болести, Медицински университет - Плевен \\ ¿Центьр по алергология и клинична имунология \\ УМБАЛ "Д-р Г. Странски" ЕАД - Плевен
}

Abstract

Aim: The aim of this study was to identify the different fungi: Alternaria, Aspergillus, Fusarium, Penicillium, Mucor and Rhizopus through skin prick test in chronic rhinosinusitis (CRS) patients and to correlate their participation in pathogenesis of chronic inflammatory nose mucous membrane changes.

Material and methods: Two groups of subjects were included:

- A control group of 25 normal individuals (14 males and 11 females from 20 to 65 year old)

- A patient group of 100 adult CRS patients ( 55 males and 45 females from 20 to 65 year old) was enrolled throughout three years. The patient group is separated on two subgroups: CRS without nasal polyposis (NP) - 70 patients and CRS with NP (30 patients).

Chronic rhinosinusitis was diagnosed based on medical history, physical exam and CT scan data.

Skin prick test to fungal allergens was performed with all patients and healthy controls.

Results: 1 . Normal control group: Skin prick test was positive in $2(8 \%)$ patients. 2. Patient group: 38 (38\%) of them were positive to allergens of fungal origin. CRS without NP was positive in $30(42,86 \%)$ patients. CRS with NP was positive in 8 $(26,67 \%)$ patients.

Discussion: Recently many discussions arise concerning the role of fungi in CRS. Positive skin prick test to one or more fungal allergens in $38 \%$ of CRS patients proves the high frequency and role of fungi in chronic inflammation pathogenesis. Profound analyses are necessary concerning role and frequency of Dematiaceous family and Aspergillus fungi in the pathologic process of chronic nasal cavities inflammation.

\section{Резюме}

Цел: Цслта на това проучване е определяне ролята на атопията към фунгите в патогенезата на ХРС.

За постигане на тази цел извършихме кожно-алергични проби към следните родове фунги: Alternaria, Aspergillus, Fusarium, Peniciullum, Mucor и Rhizopus при болни с хроничсн риносинуит (ХРС) и при здрави контроли.

\section{Въведение}

Риносинуитът е сериозен здравен проблем, чиято честота нараства успоредно с тази на алергичния ринит. Хроничният риносинуит (ХРС) е един от найчестите заболявания, свързан със значителни разходи и пряко влияние върху долните дихателни пътища (Durr 2001; Ragab 2004; Fokkens 2005). ХPC се характеризира с персистиращо хронично еозинофилно възпаление c активиране на T Ly и хиперпродукция на $\operatorname{IgE}$. Периодичните екзацербации се манифестират с неутрофилна инфилтрация на лигавицата, оток на лигавицата с полипоидно задебеляване и развитие на носна полипоза като краен стадий на заболяването (EPOS 2005; 2007). Изхождайки от една от хипотезите (Jens Ponikau), хроничния риносинуит е еозинофилно възпаление, което се дължи на неспецифичната реакция на клетките на възпалението към фунги. Разглеждайки XPC с носна полипоза, Ponikau установява специфични фунгиални ИгЕ в 44\% от болните и $29 \%$ от здравите контроли използвайки RAST test (Ponikau 1999). Направените в света проучвания относно атопията към фунги при ХРС без носна полипоза не е правена. Липсват данни относно връзката на атопия към фунги и развитието на ХРС. В България до сега не са правени проучвания в тази насока.

\section{Материал и методика}

Период на нашето проучването е 3 г. (април 2005 април 2008).

Проучването се проведе в УМБАЛ „Д-р Георги Странски“ ЕАД - Плевен, като взеха участие следните звена: УНГ-клиника, Клиника по алергология, Център 
Материал и методика: 2 групи пациенти бяха включени:

- Контролна група от 25 здрави индивиди (14 мъже и 11 жени).

- 100 пациенти с диагноза хроничен риносинуит (55 мъже и 45 жени на възраст от 20 до 65 години) бяха проследявани и изследвани в продължение на 3 години. Болните са разделени на две подгупи: 70 с ХРС без носна полипоза (НП) и 30 с XРС с носна полипоза.

Диагнозата е поставена въз основа на анамнеза, физикален преглед и данни от КТ-изследване на околоносните кухини.

Skin Prick test към гъбни причинители беше проведен на всички болни и здрави.

Резултати: 1. Контролна група: Skin prick test - позитивен при $2(8 \%)$

2. Група пациенти: При $38(38 \%)$ се установи положителен prick test към един или повече от посочените родове. Разпределението в подгрупите е: 30 (42,86\%) с ХРС без НП и $8(26,67 \%)$ с ХРС с НП.

Заключение: През последните години много дискусии обсъждат ролята на фунгите при хроничния риносинуит. Положителният Skin Prick test към един или няколко родове при $38 \%$ от болните, доказва високата честота и ролята им в патогенезата на хроничното възпаление. Нужни са по-задълбочени проучвания върху ролята и честотата на фунгите от fam. Dematiaceous и род Aspergillus в патологичния процес при хроничното възпаление на носа и околоносните кухини. по клинична имунология и Цитологична лаборатория към Онкологичен център.

Изследвани са $100(\mathrm{n}=100)$ болни с диагноза хроничен риносинуит и $25(\mathrm{n}=25)$ здрави контроли. Групата на болните е разделена на две подгрупи:

1. ХРС без носна полипоза $(\mathrm{n}=70)$;

2. ХРС с носна полипоза $(\mathrm{n}=30)$.

Разпределение по пол на изследваните групи е както следва:

I. Група на болните: 55 жени и 45 мъже.

Разпределение в подгрупите е:

1. ХРС без полипоза - 49 жени и 21 мъже;

2. ХРС с полипоза - 16 мъже и 14 жени.

II. Контролна група: 14 жени и 11 мъже.

Разпределение по възраст: $20-65$ г.

На всички пациенти и контроли се извършиха кожноалергични проби (КАП) към следните родове фунги: Alternaria, Aspergillus, Fusarium, Mucor, Rhizopus, Penicillium (фиг. 1).

Пробите се отчитат на 40 мин. и 24 ч.
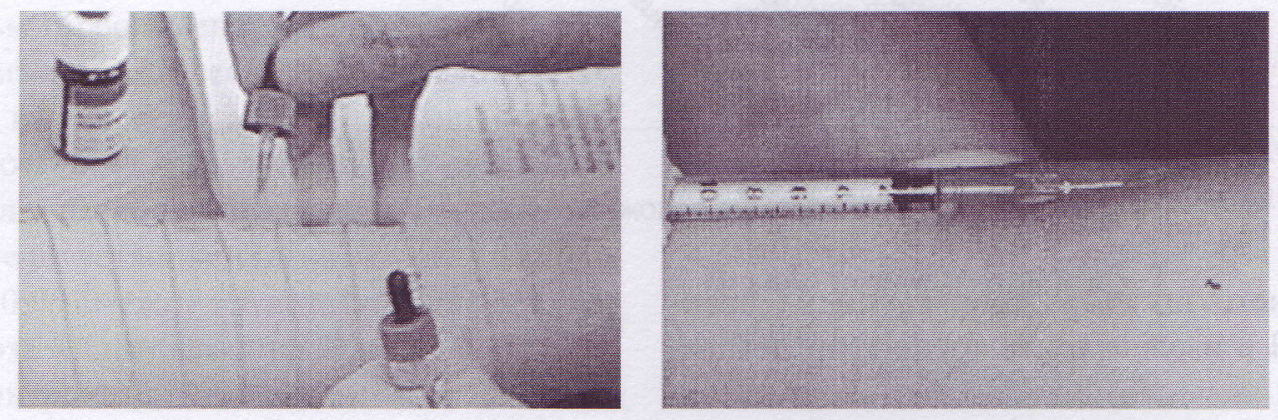

Фиг. 1. Техника на кожно-алергично тестуване

\section{Резултати}

Изследвайки двете групи пациенти, се установи следното: в групата на болните тридесет и осем (38\%) от случаите са положителни към един или няколко рода, а останалите шестдесет и два $(62 \%)$ - отрицателни. Резултатите в подгрупата на болните са следните:

1. ХРС без полипоза - тридесет $(42,86 \%)$ болни са позитивни, а останалите четиридесет $(57,14 \%)$ са негативни.

2. ХРС с назална полипоза - осем $(26,67 \%)$ болни са с положителни КАП към един или повече родове; останалите двадесет и двама $(73,33 \%)$ болни са с отрицателни проби.

Изследването на контролната група установи положителни проби към един род фунги при двама $(8 \%)$ пациенти и отрицателни проби при останалите двадесет и три (92\%) случаи. Единият (4\%) пациент има положителен КАП към Alternaria, а другият (4\%) към Penicillium. Положителните резултати са представени на фиг. 2.

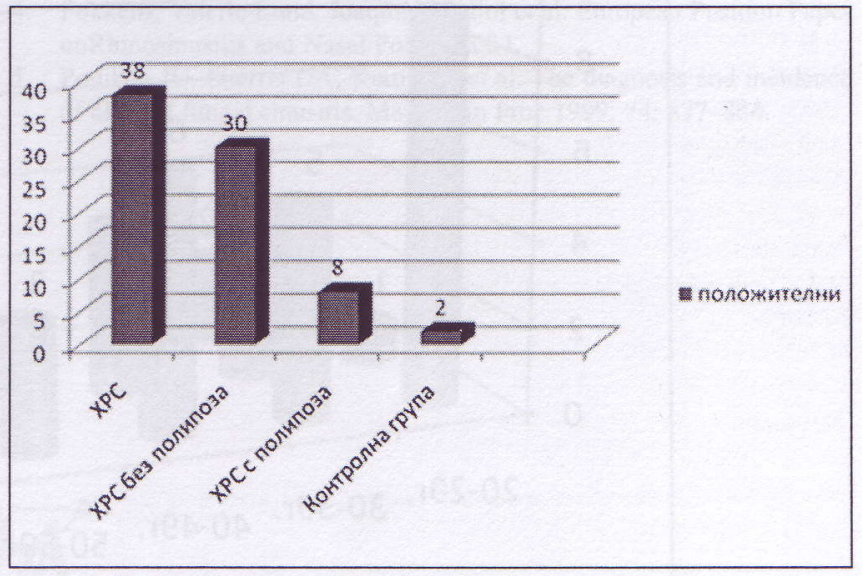

Фиг. 2. Разпределение на положителните фунгиални КАП сред изследваните групи и подгрупи

Разпределение на положителните проби в подгрупите на болните с ХРС към изследваните родове фунги е както следва: 


\section{Род фунги}

Aspergillus

Alternaria

Penicillium

Fusarium

Mucor

Rhizopus

\section{XРС без полипоза XPC с полипоза}

$\begin{array}{rr}8 & 6 \\ 6 & 4 \\ 15 & 5 \\ 14 & 2 \\ 3 & 0 \\ 4 & 0\end{array}$

Разпределението по пол между подрупите на групата на болните по отношение на позитивните проби към изследваните родове е:

Разпределение на положителните КАП в изследваните групи по род фунги е представено на фигуpa 3.

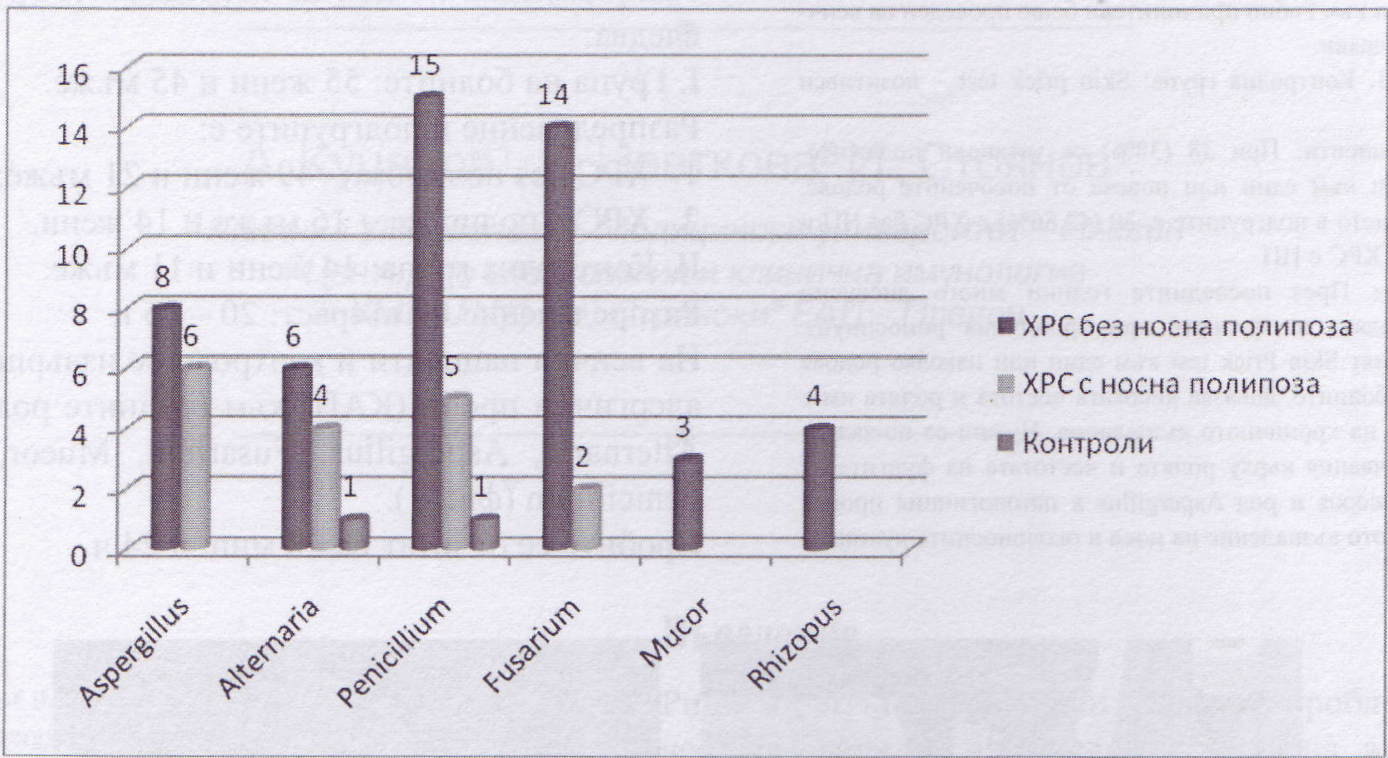

Фиг. 3. Разпределение на положителните КАП по родове фунги

Разпределението по възрастови групи на позитивните КАП в изследваните групи е представе-

но на фигура 4.

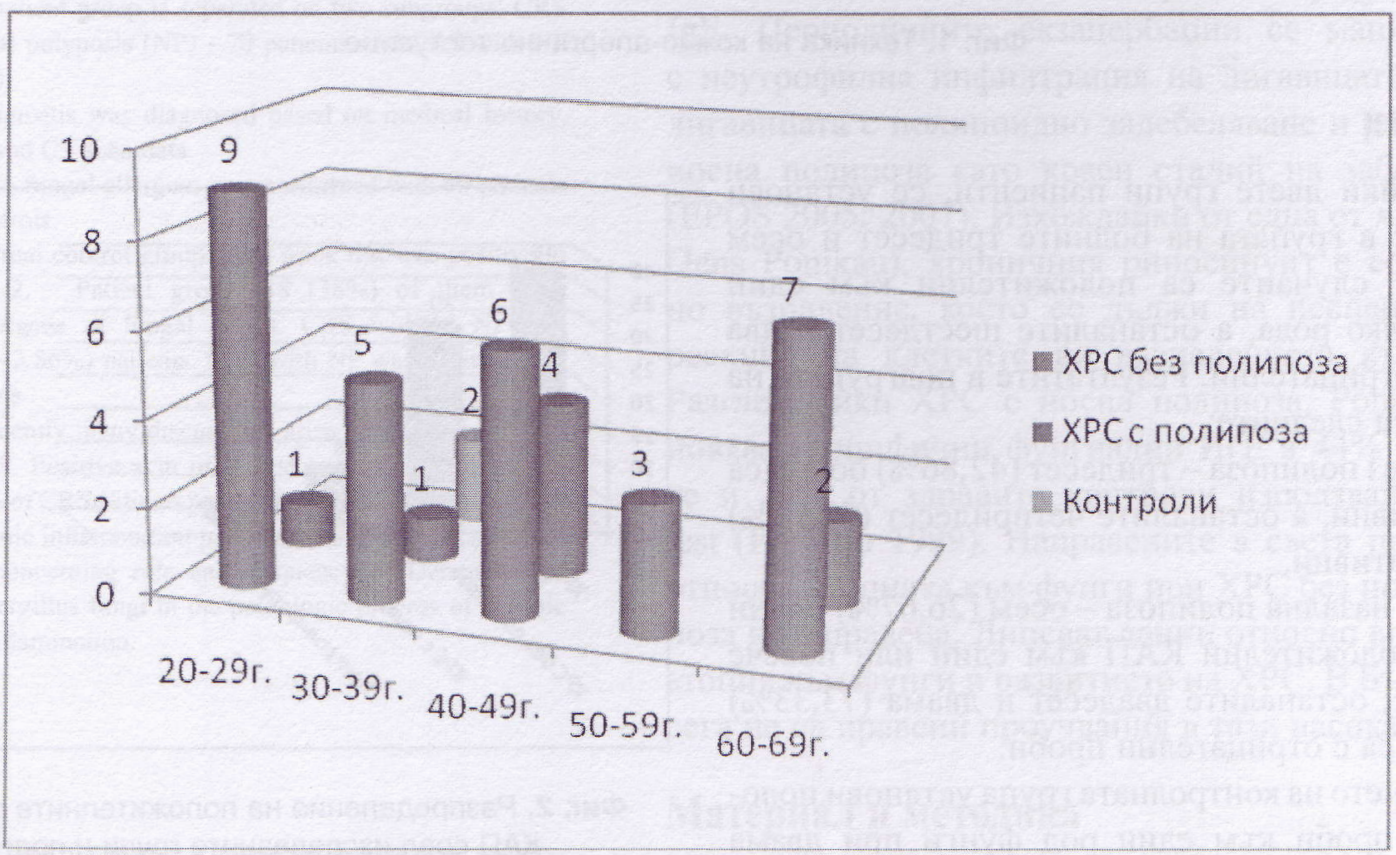

Фиг. 4. Разпределение по възраст на позитивните КАП сред изследваните групи пациенти

При сравняване на резултатите статистически в изследваните групи се установи статистически значима разлика \{Anova Table Test $(\mathrm{p}=0,0001)$ и Kruskal-Wallis Tests $(p=0,0001)\}$ между групата 
на болните и контролите по показател кожно-алергични проби. Липсва статистически достоверна разлика $(\mathrm{p}>0,05)$ между подгрупите на XРС по показател положителни фунгиални КАП.

\section{Обосъжане}

Проучването установи позитивни КАП (наличие на специфични ИгЕ) към един или няколко родове при 38 (38\%) от болните с ХРС и 2 (8\%) от контролите. Резултатите са сравними с тези на Ponikau (1999), въпреки че е изпозван skin-prick test за косвено определяне на специфични фунгиални ИгЕ. В подгрупите на ХРС положителни фунгиални КАП се установиха при 30 (42,86\%), докато при болните с полипозен ХРС в 8 (26,67\%). Съществува различие и по отношение на родовете фунги в подгрупите на ХРС. При ХРС без полипоза най-често положителни КАП се установиха към род Penicillium, докато при тези с полипоза към род Aspergillus. Съществува разлика и по отношение на относителния дял на болните с позитивни към гореспоменатите родове фунги по възрастов признак. Най-често положителни КАП установихме във възрастта 20-39 г. при болните без полипоза и 40-49 г. при тези с полипоза. Въпреки различията статистическата обработка на резултатите не установи статистическа значима разлика $(\mathrm{p}>0,05)$ между групата на ХРС без и с носна полипоза. Съществува такава между болните с ХРС и контролите.

\section{Изводи}

1. КАП към фунги могат да се използват като диагностично средство при ХРС.

2. КАП доказаха специфичен ИгЕ медииран отговор към изследваните родове фунги в $38 \%$ от болните от ХРС.

3. Необходимо е да се оценява ролята на атопията към фунги и при болни с ХРС без носна полипоза.

4. Атопията към фунги се установи по-често при болните с ХРС без носна полипоза.

5. Липсата на статистически достоверна разлика $(\mathrm{p}>0,05)$ между двете подгрупи на ХРС ни кара да заключим, че позитивните фунгиални КАП не могат да се използват като прогностично средство за развитие на ХРС с полипоза.

6. Най-често атопия се установи към род Aspergillus при ХРС с носна полипоза и към род Penicillium при ХРС без полипоза.

7. Изследването на КАП към фунги може да бъде използвано като средство за идентификация на род/ове фунги.

8. Статистически достоверната разлика по отношение на позитивни КАП към фунги между болни и здрави доказва патологичната им роля в ХРС, изразяваща се с ИгЕ- медииран имунен отговор.

\section{Литература:}

1. Durr DG, Desrosiers MY, Dassa C. Impact of rhinosinusitis in health care delivery: the Quebec experience. J Otolaryngol 2001; 30:93.

2. Ragab A, Clement P, Vincken W. Objective assessment of lower airway involvement in chronic rhinosinusitis. Am J Rhinol 2004; 18: 15-21.

3. Fokkens W, Lund V, Bachert C, et al. EAACI position paper on rhinosinusitis and nasal polyps executive summary. Allergy 2005; 60 : 583-601.
4. Fokkens, Valerie Lund, Joaquim Mullol et al. European Position Paper onRhinosinusitis and Nasal Polyps 2007.

5. Ponikau JU, Sherris DA, Kern EB, et al. The diagnosis and incidence of allergic fungal sinusitis. Mayo Clin Proc 1999; 74: 877-884. 